\title{
lonically Cross-Linked Chitosan Nanoparticles for Sustained Delivery of Docetaxel: Fabrication, Post-Formulation and Acute Oral Toxicity Evaluation
}

This article was published in the following Dove Press journal:

International Journal of Nanomedicine

Muhammad Ahmad

Mahmood 1,2

Asadullah Madni (D)

Mubashar Rehman (D) ${ }^{3}$

Muhammad Abdur Rahim'

Abdul Jabar'

'Department of Pharmacy, The Islamia University of Bahawalpur, Bahawalpur

63100, Pakistan; ${ }^{2}$ Drug Testing

Laboratory, Bahawalpur 63100, Pakistan;

${ }^{3}$ Faculty of Pharmacy, University of

Central Punjab, Lahore 54000, Pakistan
Correspondence: Asadullah Madni Department of Pharmacy, The Islamia University of Bahawalpur, Khawaja Fareed Campus, Railway Road, Bahawalpur, Punjab, Pakistan

Tel +92 629255243

Fax +92 629255565

Email asadpharmacist@hotmail.com
Introduction: Polymeric nanoparticles are potential carriers for the efficient delivery of hydrophilic and hydrophobic drugs due to their multifaceted applications. Docetaxel is relatively less hydrophobic and twice as potent as paclitaxel. Like other taxane chemotherapeutic agents, docetaxel is not well tolerated and shows toxicity in the patients. Nanoencapsulation of potent chemotherapeutic agents has been shown to improve tolerability and therapeutic outcome. Therefore, the present study was designed to fabricate chitosan and sodium tripolyphosphate (STPP) based on ionically cross-linked nanoparticles for sustained release of docetaxel.

Methods: Nanoparticles were prepared by the ionic-gelation method by dropwise addition of the STPP solution into the chitosan solution in different ratios. CNPs were characterized for post-formulation parameters like size, zeta potential, scanning electron microscope (SEM), FTIR, DSC/TGA, pXRD, and in-vitro drug release, as well as for acute oral toxicity studies in Wistar rats.

Results and discussion: The optimized docetaxel loaded polymeric nanoparticles were in the size range $(172.6 \mathrm{~nm}-479.65 \mathrm{~nm})$, and zeta potential $(30.45-35.95 \mathrm{mV})$ required to achieve enhanced permeation and retention effect. In addition, scanning electron microscopy revealed rough and porous surface, whereas, FTIR revealed the compatible polymeric nanoparticles. Likewise, the thermal stability was ensured through DSC and TG analysis, and powder X-ray diffraction analysis exhibited solid-state stability of the docetaxel loaded nanoparticles. The in-vitro drug release evaluation in phosphate buffer saline ( $\mathrm{pH} 7.4$ ) showed sustained release pattern, i.e. 51.57-69.93\% within $24 \mathrm{hrs}$. The data were fitted to different release kinetic models which showed Fickian diffusion as a predominant release mechanism $\left(R^{2}=0.9734-0.9786, \mathrm{n}=0.264-0.340\right)$. Acceptable tolerability was exhibited by acute oral toxicity in rabbits and no abnormality was noted in growth, behavior, blood biochemistry or histology and function of vital organs.

Conclusion: Ionically cross-linked chitosan nanoparticles are non-toxic and biocompatible drug delivery systems for sustained release of chemotherapeutic agents, such as docetaxel. Keywords: tripolyphosphate, ionic gelation, sustained release, targeting, biocompatible, biodegradable

\section{Introduction}

Cancer is a disease characterized by uncontrolled growth of cells that are capable of invading, and metastatizing the surrounding tissue. It is the second leading cause of 
mortality and accounts for 1 in every 6 deaths in the world. The majority of the cancer-related deaths occur in low- and middle-income countries, it is posing a higher impact on the total economy of the world. ${ }^{1,2}$ Chemotherapy is the main component of cancer treatment either alone or in combination with other treatment options. ${ }^{3}$ Although anti-cancer agents are available for chemotherapy of various types of cancer, yet inaccessibility to the target site leads to insufficient amount of drug in cancerous cells. Passive targeting facilitates drug delivery at the site of action without requiring any surface decoration or ligand attachment (active targeting). Cancer has leaky vasculature which facilitates the entry of nanoparticles and an increased amount of vascular permeability factors (bradykinin, peroxynitrite \& nitric oxide). Additionally, the immature lymphatic system is incapable of drainage from interstitial spaces. Collectively, these factors lead to prolonging the stay of drug carriers at cancer site which is also known as enhanced permeability and retention (EPR) effect. Previous literature reports that drug carriers with an average diameter of approximately $400 \mathrm{~nm}$ are good candidates of passive targeting by the EPR effect. ${ }^{4,5}$

Polymeric nanoparticles (PNPs) of a particular size range have relatively higher capability to accumulate at the tumor site without affecting normal tissues. ${ }^{6}$ For biomedical applications, biodegradable polymers based PNPs are used to modify solubility, permeability and bioavailability of therapeutic agents. ${ }^{7}$ Chitosan is a nontoxic biopolymer of natural origin derived by the deacetylation of chitin and is widely employed for various drug delivery purposes. $^{8}$ It is obtained from crustacea shells, insect cuticles, and cell walls of some fungi and is straight-chain amino polysaccharide (poly- 1,4-D-glucosamine) with many features which are favorable for its use in drug delivery. ${ }^{9}$ It is being highly explored for its application in oral delivery. ${ }^{10}$ Not only chitosan, but its derivatives like glycol chitosan, thiolated chitosan, arginine-chitosan, carboxymethyl chitosan, aminated chitosan are also being explored for the drug delivery application. ${ }^{11,12}$ Chitosan undergoes protonation in an acidic environment and provides favorable release at low $\mathrm{pH}$. As the tumor microenvironment has acidic $\mathrm{pH}$ due to poor drainage of wastes, chitosan may be employed for tunable drug delivery to cancer. $^{13}$

Docetaxel (DTXL) has a taxane ring that promotes the assembly of microtubules and stabilizes them, thus, preventing them from depolarization. ${ }^{14}$ It exhibits higher cellular uptake and intracellular retention than paclitaxel due to its broader cell cycle activity and more binding affinity towards $\beta$-tubulin. It used for chemotherapy of ovarian, prostate, breast, gastric and non-small cell lung cancer. $^{15}$ It is twice as potent and relatively less hydrophobic than the paclitaxel. ${ }^{16}$ Docetaxel is used as injection via intravenous route but limited aqueous solubility and systemic toxicity are main problems associated with clinical use of DTXL. These features of DTXL make it a good candidate for delivery through PNPs to eradicate any of the said problems. ${ }^{17,18}$ Therefore, the present study was aimed to formulate the chitosan-based PNPs to enhance solubility and sustain delivery of docetaxel for the treatment of various types of cancer.

\section{Materials and Methods Materials}

Docetaxel (DTXL) was purchased from Mesochem Technology Co., Ltd, Beijing, China. Low molecular weight chitosan and sodium tripolyphosphate (STPP) were procured from Sigma-Aldrich, India. Ethanol was obtained from Merck, Germany, and acetic acid from VWR chemicals, USA. Distilled water was prepared by using the distillation apparatus in the Pharmaceutics Research Laboratory, The Islamia University of Bahawalpur, Bahawalpur, Pakistan. All the chemicals used were of analytical grades and used as received without further processing.

\section{Preparation of Polymeric Nanoparticles}

Chitosan polymeric nanoparticles (CNPs) were fabricated by the ionic-gelation method with minor modifications. ${ }^{19}$ Chitosan was dissolved overnight in $1.5 \% \mathrm{v} / \mathrm{v}$ acetic acid solution in distilled water. Varied concentrations were made of STPP in water and DTXL in ethanol in separate vessels (Table 1). DTXL and STPP solutions were mixed followed by drop-wise addition of the aforementioned mixture into chitosan solution with continuous stirring at room temperature. The mixture was subjected to stirring (900 rpm, $45 \mathrm{mins}$ ) followed by centrifugation (11,000 rpm, $30 \mathrm{mins})$ and nanoparticles were obtained as a fine pellet. The obtained nanoparticles were lyophilized for further characterization.

\section{Percentage Yield (\%)}

Percentage yield (\%) of the nanoparticles produced by a specific method is an important parameter with the pharmaceutical point of view as it may be helpful to predict the probability of industrial scale-up and commercial feasibility of a process. A process with the highest 
yield is considered preferable. The percentage yield was calculated to determine the efficiency of methods to generate the product. The total amount of powder obtained after lyophilization (CHRIST alpha 1-4 LD, UK) was weighed using analytical weighing balance (Shimadzu, Japan, AUW 220) and percentage yield was calculated using the following formula. ${ }^{20}$

$$
\text { percentage yield }=\frac{\text { Quantity of CNPs obtained }}{\text { total mass of all ingredients }} \times 100
$$$$
(\text { Chitosan + STPP + Drug })
$$

\section{Particle Size, Polydispersity Index (PDI), and Zeta Potential Analysis}

The particle size of PNPs is the performance determinant of their efficiency as passive targeting to cancer site while PDI and zeta potential are indicators of homogeneity and colloidal stability, respectively. ${ }^{21}$ For the evaluation of particle size, PDI, and zeta potential Zeta Sizer Nano (ZS-90, Malvern, UK) was used.

\section{Entrapment Efficiency and Drug Loading Capacity}

Entrapment efficiency (EE) and loading capacity (LC) were calculated by the indirect method. In this method, PNPs formulation is subjected to centrifugation and the un-entrapped fraction of drug was quantified in the supernatant by using a calibration curve. The whole analysis was done in triplicate to minimize handling errors. EE is the percentage of the drug, from total drug initially added the drug, that is successfully encapsulated within the system, whereas, LC is the percentage of the drugs that is successfully loaded on the specific mass of CNPs. ${ }^{7,22}$

$\begin{aligned} \text { L.C }= & \frac{\text { total amount of drug added }- \text { amount of unentrapped drug }}{\text { total mass of CNPs }} \\ & \times 100 \quad\end{aligned}$

$\begin{aligned} \text { E.E }= & \frac{\text { total amount of drug added }- \text { amount of unentrapped drug }}{\text { total amount of drug added }} \\ & \times 100 \quad \text { to }\end{aligned}$

\section{Scanning Electron Microscopic (SEM) Studies}

Scanning Electron Microscopic (SEM) studies were used to evaluate the morphology and surface characteristics of DTXL loaded CNPs. ${ }^{23}$ The lyophilized powder was placed on a piece of the electro-conductive chip of silicon over the top of the metal stub (aluminum). The samples were coated on the stubs and examined under Field Emission Scanning Electron Microscope (FESEM, JSM-5910, JEOL, Japan) at different magnifications using an electron acceleration voltage $10 \mathrm{kV}$.

\section{Thermal Stability (DSC and TGA)}

The thermal stability of the DTXL, chitosan, STPP, physical mixture and selected formulation (CNP3) was estimated through differential scanning calorimetry (DSC) and thermogravimetric analysis (TGA). The DSC analysis was done to evaluate phase transition in the sample as a function of time and temperature in a controlled atmosphere through the graph between temperature $\left({ }^{\circ} \mathrm{C}\right)$ and flow of heat $(\mathrm{w} / \mathrm{g})$. The thermogravimetric analysis was done to evaluate the percent weight loss by increasing temperature through the graph between temperature $\left({ }^{\circ} \mathrm{C}\right)$ and percent weight loss. ${ }^{21}$

\section{Powdered X-Ray Diffraction Analysis (PXRD)}

PXRD analysis of DTXL, chitosan, STPP, physical mixture comprising equal amounts of components and the selected formulation (CNP5) was performed to elucidate the physical state of the individual components, physical mixture and the formulation. The X-ray diffractograms based on the Bragg's law were obtained by using a PXRD diffractometer (Bruker Axs, D8 Advance, Germany) with $\mathrm{CuK} \alpha$ radiation, $45 \mathrm{kV}$ monochromatic voltage and $40 \mathrm{~mA}$ electric current. The range for $2 \theta$ diffraction angle was from $10^{\circ}$ to $60^{\circ} .^{24}$

\section{Fourier Transform Infrared Spectroscopy (FTIR) Analysis}

The FTIR analysis was performed to evaluate interactions or compatibility of the formulation components which in turn highlights the stability of the developed system. ${ }^{25}$ FTIR spectroscopic analysis of DTXL, chitosan, STPP, physical mixture (DTXL, chitosan and STPP in 1:1:1) and a selected formulation (CNP3) was performed by Attenuated Total Reflectance (ATR) assembly with diamond crystal (Bruker, Tensor 27 series, USA). The system was set to 32 scans for each sample for a better scan and reliable results.

\section{In-vitro Drug Release Studies and Kinetic Modeling}

All formulations were evaluated for in-vitro release behavior by dissolution studies and release mechanism by application of 
the kinetic modeling approach. For this purpose, developed formulations were taken equivalent to $2 \mathrm{mg}$ DTXL and were dispersed in $2 \mathrm{~mL}$ of the Phosphate Buffer Saline (PBS) of $\mathrm{pH}$ 7.4. Dialysis membrane (Spectrum ${ }^{\circledR}$ ) with $8-10$ KDa cut off value was used in this study. The membrane was soaked for 3 hrs in distilled water before the initiation of experimentation to clear all the pores. It was cut to a suitable size and formulation equivalent to $2 \mathrm{mg}$ DTXL suspended in PBS 7.4 is added in it. Both ends were tied and it was placed in $600 \mathrm{~mL}$ dissolution medium (PBS 7.4 containing $0.5 \%$ tween 80 to maintain sink conditions) at $37 \pm 0.5^{\circ} \mathrm{C}$. USP type II apparatus (paddle apparatus) was used for the study and paddles were rotated at $50 \mathrm{rpm}$. Samples of $3 \mathrm{~mL}$ were withdrawn at predefined intervals and dissolution vessels were replenished with an equal volume of fresh dissolution medium to maintain sink conditions. Taken samples were filtered through $0.45 \mu \mathrm{m}$ Nylon syringe filters (Membrane Solution, USA) and analyzed using UV-Spectrophotometer (IRMECO-U2020) at $\lambda_{\max } 230$ nm. Readings were taken in triplicate to minimize error. ${ }^{26}$ Calculated cumulative percentage release was evaluated for each sample using different kinetic models, such as zero order, first order, Higuchi and Korsmeyer-Peppas model, with DDSolver.xla extension of Microsoft Excel.

\section{Acute Oral Toxicity Study Evaluation}

The oral acute toxicity study was conducted according to the OECD (Organization for Economic Co-operation and Development) animal welfare guidelines and Declaration of Helsinki for ethical principals in medical research in humans and, where appropriate, on animals experimentation. ${ }^{27}$ The approval of the study was obtained from the Pharmacy Research Ethics Committee (PREC), Faculty of Pharmacy and Alternative Medicine, The Islamia University of Bahawalpur (letter no. 90/S-2018/PREC dated 15-012018). Eight (08) male healthy Wistar rats were selected for the study and kept in clean cages for 14 days. All the rats were given free access to water and diet throughout the study. The weight of the rats was determined before dosing. Rats were divided into two groups randomly, each group containing four rats. Group I was administered with Chitosan nanoparticles at $2 \mathrm{~g} / \mathrm{kg}$ of the body weight. Group II was used as the control for the study, as this group was administered with water and food only. The parameters checked were mortality rate, physical appearance, and body weight of the animals. After the time suggested by the OECD guidelines, i.e. 14 days animal's blood was taken for the biochemical analysis and the rats were sacrificed for the histopathological examination of the vital organs.

\section{Statistical Analysis}

One-tailed $t$-test was applied for the statistical analysis $(n=3)$. The statistical analysis was applied on percentage yield, entrapment efficiency, loading capacity, particle size, PDI, and zeta potential studies. The $p$ values were calculated to evaluate the effect of varying concentrations of STPP on the CNPs (CNP1-CNP5).

\section{Results and Discussion}

In the present study, DTXL loaded chitosan nanoparticles (CNPs) were prepared by ionic-gelation method by varying ratio of STPP (Table 1), and then characterized for various parameters.

\section{Preparation of Polymeric Nanoparticles}

Ionic-gelation method relies on the instituting a sol-gel transition of chitosan in a suitable solution under the threshold of macroscopic gelation. The stated method is a spontaneous and CNPs are formed immediately upon addition of STPP. Previously, a 3:1 volume ratio of Chitosan and STPP as well as the weighed ratio of chitosan and STPP as 3:1 to 6:1, were regarded as best suitable for the said purpose. ${ }^{28}$ In the current study, the volume ratio of 2.5:1 was used that lies close to the previously stated value and the weight ratio was from 2.5:1 to 7.5:1. Additionally, parameters of stirring speed and time were set at $900 \mathrm{rpm}$ and 35 mins.

Table I Composition of Chitosan Loaded Nanoparticles Containing Docetaxel

\begin{tabular}{|c|c|c|c|}
\hline Formulation Code & Chitosan Concentration $^{a}$ & DTXL Concentration ${ }^{b}$ & STPP Concentration ${ }^{c}$ \\
\hline CNPI & $75 \mathrm{mg} / 25 \mathrm{~mL}$, i.e. $3 \mathrm{mg} / \mathrm{mL}$ & $10 \mathrm{mg} / 3 \mathrm{~mL}$ & $10 \mathrm{mg} / 10 \mathrm{~mL}$ \\
\hline CNP2 & $75 \mathrm{mg} / 25 \mathrm{~mL}$, i.e. $3 \mathrm{mg} / \mathrm{mL}$ & $10 \mathrm{mg} / 3 \mathrm{~mL}$ & $15 \mathrm{mg} / 10 \mathrm{~mL}$ \\
\hline CNP3 & $75 \mathrm{mg} / 25 \mathrm{~mL}$, i.e. $3 \mathrm{mg} / \mathrm{mL}$ & $10 \mathrm{mg} / 3 \mathrm{~mL}$ & $20 \mathrm{mg} / 10 \mathrm{~mL}$ \\
\hline CNP4 & $75 \mathrm{mg} / 25 \mathrm{~mL}$, i.e. $3 \mathrm{mg} / \mathrm{mL}$ & $10 \mathrm{mg} / 3 \mathrm{~mL}$ & $25 \mathrm{mg} / 10 \mathrm{~mL}$ \\
\hline CNP5 & $75 \mathrm{mg} / 25 \mathrm{~mL}$, i.e. $3 \mathrm{mg} / \mathrm{mL}$ & $10 \mathrm{mg} / 3 \mathrm{~mL}$ & $30 \mathrm{mg} / 10 \mathrm{~mL}$ \\
\hline
\end{tabular}

Notes: ${ }^{a} \ln 25 \mathrm{~mL}$ of $1.5 \%$ acetic acid solution in water to produce the concentration of $3 \mathrm{mg} / \mathrm{mL}$. ${ }^{\mathrm{b}} / \mathrm{n} 3 \mathrm{~mL}$ of ethanol. ${ }^{\mathrm{c}} \mathrm{ln} 10 \mathrm{~mL}$ of distilled water. 


\section{Particle Size, PDI, and Zeta Potential Analysis}

A size of 200 to $300 \mathrm{~nm}$ is regarded as suitable for crossing biological barriers, avoid RES and to escape glomerular filtration. ${ }^{29}$ Size up to $400 \mathrm{~nm}$ is also considered acceptable (evaluated in case of liposomes). ${ }^{30}$ A study reported suitable size for EPR as $10-500 \mathrm{~nm}^{31}$ In this study, particle sizes of developed CNPs were in nanosize range $(172.6 \mathrm{~nm}$ to $479.65 \mathrm{~nm})$ and fulfill the requirement of EPR to enhanced antitumor efficacy. The size of nanoparticles was found to be directly related to the varied ratio of chitosan and STPP as increasing the concentration STPP leads to increased particle size $(\mathrm{p}<0.05)$. The obtained results were in accordance with the results reported by Sreekumar et al, 2018, who reported that proportions of chitosan and STPP collectively affect the particle size and the size of nanoparticles increases by increasing any of the two components. ${ }^{32}$ The PDI of the developed nanoparticles was less than 0.5 in all cases. However, relatively more monodisperse systems (PDI = $0.219 \pm 0.004)$ were achieved in CNP3 prepared with $20 \mathrm{mg} \mathrm{STPP} .^{33}$ PDI increased at both above and below this concentration. Zeta potential of the developed chitosan nanoparticles was found to be $30.45 \mathrm{mV}-35.95 \mathrm{mV}$. The zeta potential value of greater than $30 \mathrm{mV}$ depicts excellent colloidal stability wherein positive potential is due to the presence of positively charged chitosan in CNPs. ${ }^{31,34,35}$ It can be seen in the results that the zeta potential value decrease by increasing the STPP concentration which is similar to previous reports. ${ }^{36}$ This may be due to higher degree of gelation of the nitrogen of chitosan to the phosphate of STPP, as reported previously in case of nitrogen of chitosan and phosphate of DNA molecules. ${ }^{37}$

\section{Entrapment Efficiency and Drug Loading Capacity}

The entrapment efficiency of the chitosan/STPP nanoparticles was in the range of $56.39 \%$ to $72.73 \%$ and loading efficiency ranged from $7.88 \%$ to $9.35 \%$ (Table 2). Initially, entrapment efficiency was directly proportional to the concentration of STPP as it increased significantly $(\mathrm{p}<0.05)$ by increasing the STPP concentration up-to a certain level, i.e. CNP3 $(20 \mathrm{mg} / 10 \mathrm{~mL})$, which corresponds optimized ionic gelation of the components. Above this value, entrapment efficiency decreased which can be attributed to the shells becoming thicker with the STPP concentration and relative competition between the DTXL and STPP within the nanoparticles. ${ }^{38} \mathrm{~A}$ similar response was also observed for the encapsulation of protein in CNPs. ${ }^{39}$ By increasing drug concentrations, the entrapment efficiency and loading efficiency were decreased. ${ }^{13}$

\section{Scanning Electron Microscopic (SEM) Studies}

The scanning electron microscopy showed round shape with the porous and rough surface of two PNP formulations at different magnifications (Figure 1). This is in agreement with previous studies that chitosan PNPs are round in shape and their surface characteristics depend upon the ratio of components. ${ }^{40}$ The morphology of PNPs is also important from pharmacokinetics perspective and round shape PNPs are desirable. ${ }^{41,42}$

\section{Thermal Analysis (DSC and TGA)}

The initial mass loss was due to the moisture loss at $58.01^{\circ} \mathrm{C}$ and $92.37^{\circ} \mathrm{C}$ in the physical mixture, and formulation (Figure 2). The differential scanning calorimetric analysis demonstrated that transition of phase from hard solid powder form into plastic flakes takes place at $174.01^{\circ} \mathrm{C}$ to $299.33^{\circ} \mathrm{C}$, whereas, the abrupt declination of weight due to the phase transition temperature of drug was detected at $224.59^{\circ} \mathrm{C}$ by the thermogravimetric analyzer. The destruction of the DTXL was observed at $419.01^{\circ} \mathrm{C}$ and $431.80^{\circ} \mathrm{C}$ by differential scanning calorimetry and thermogravimetric analysis (Figure 2). Phase transition temperature of the physical mixture was observed in the range of

Table 2 Evaluation of Different Formulation Parameters of Docetaxel Loaded Nanoparticles

\begin{tabular}{|l|l|l|l|l|l|l|}
\hline Formulation Code & $\begin{array}{l}\text { Percentage Yield } \\
\text { (\%) } \pm \text { SD }\end{array}$ & $\begin{array}{l}\text { Entrapment Efficiency } \\
\text { (\%) } \pm \text { SD }\end{array}$ & $\begin{array}{l}\text { Loading Capacity } \\
\text { (\%) } \pm \text { SD }\end{array}$ & Particle Size \pm SD & PDI \pm SD & $\begin{array}{l}\text { Zeta } \\
\text { Potential } \pm \text { SD }\end{array}$ \\
\hline CNPI & $66.79 \pm 0.008$ & $60.124 \pm 0.93$ & $9.002 \pm 0.14$ & $172.6 \pm 4.08$ & $0.319 \pm 0.013$ & $35.95 \pm 0.69$ \\
CNP2 & $73.79 \pm 0.012$ & $66.758 \pm 1.31$ & $9.025 \pm 0.18$ & $195.3 \pm 1.92$ & $0.448 \pm 0.012$ & $33.65 \pm 0.37$ \\
CNP3 & $77.81 \pm 0.022$ & $72.728 \pm 1.12$ & $9.347 \pm 0.14$ & $270.9 \pm 5.31$ & $0.219 \pm 0.004$ & $33.0 \pm 0.82$ \\
CNP4 & $69.20 \pm 0.016$ & $64.022 \pm 0.82$ & $9.252 \pm 0.12$ & $337.4 \pm 2.45$ & $0.398 \pm 0.016$ & $33.5 \pm 0.57$ \\
CNP5 & $71.57 \pm 0.005$ & $56.393 \pm 0.61$ & $7.880 \pm 0.09$ & $479.65 \pm 11.47$ & $0.487 \pm 0.011$ & $30.45 \pm 0.37$ \\
\hline
\end{tabular}




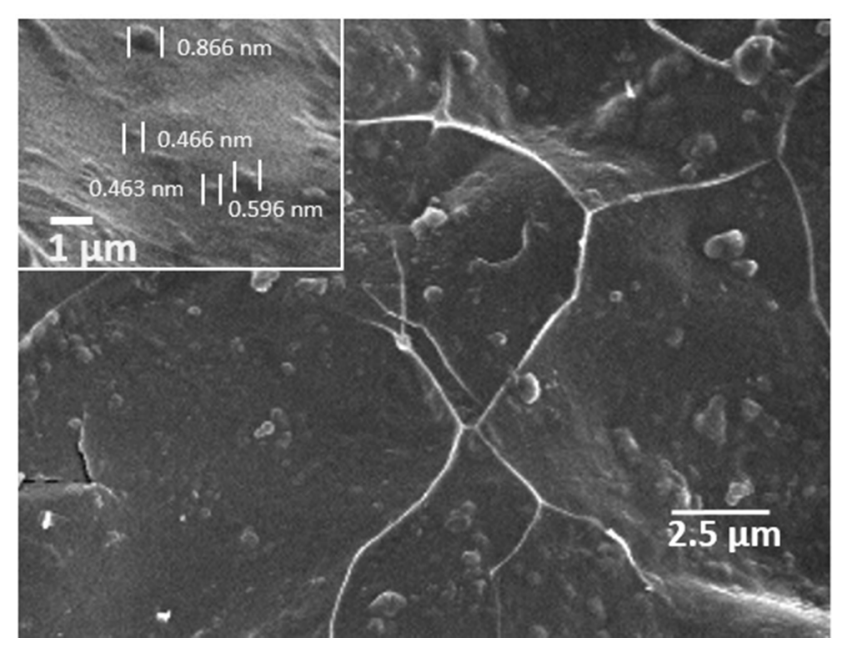

Figure I Scanning electron micrographs of docetaxel loaded chitosan nanoparticles.

260.75-320.27 ${ }^{\circ} \mathrm{C}$. Likewise, the drug peak of phase transition temperature was also found in the physical mixture at $261.75^{\circ} \mathrm{C}$ of TGA. The destructive peak in the DSC graph of the physical mixture was almost identical to the drug. The formulation showed phase transition temperature in the

\section{$\underline{\text { DSC }}$}

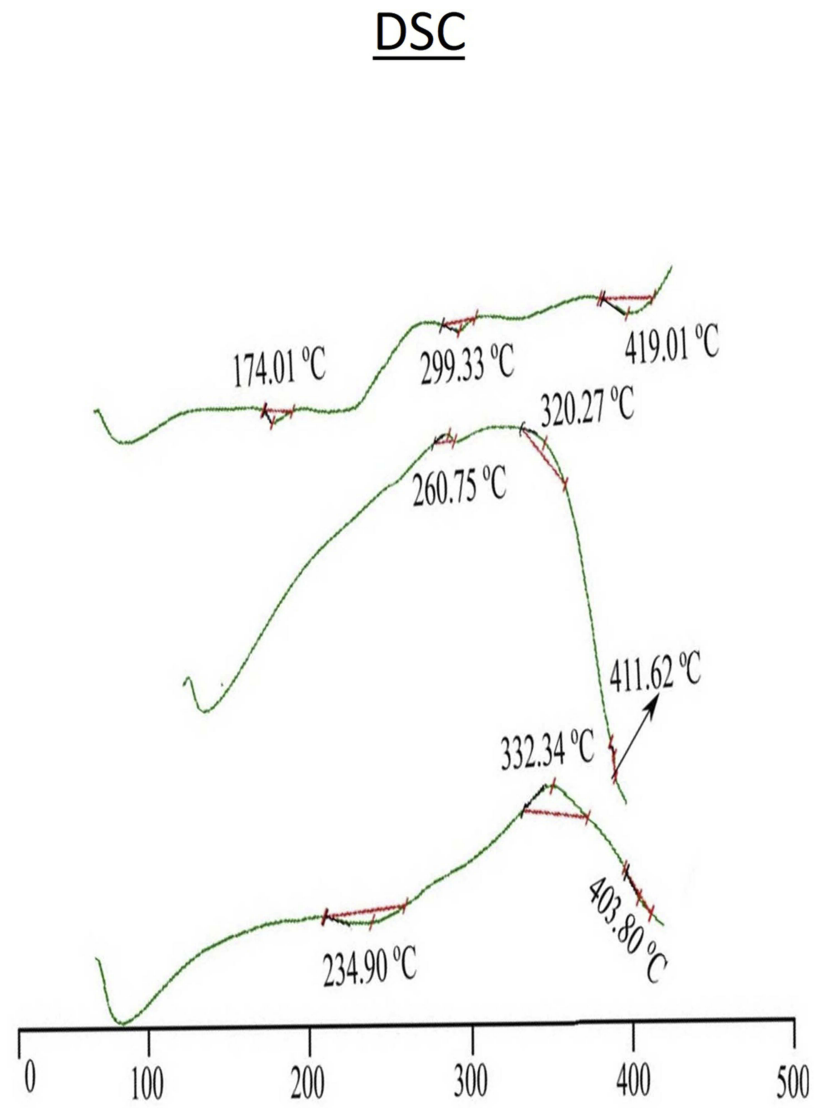

range of $234.90-323.34^{\circ} \mathrm{C}$ in DSC analysis and did not show prominent drug peak. Likewise, the TGA graph of the PNPs showed the DTXL peak with slight shifting. The absence of drug peak in DSC and slight shifting in TGA reveals the efficient entrapment of the drug within the nanoparticulate system and thermal stability of the developed nanoparticles as shown in Figure $2 .^{43}$

\section{Powdered X-Ray Diffraction Analysis (PXRD)}

The distinct and sharp peaks of DTXL, chitosan, and STPP were observed which represented their crystalline nature with insignificant amorphous contents (Figure 3) in agreement with previous literature on chitosan-based PNPs. Likewise, the distinct and sharp peaks of DTXL and STPP were also observed in the physical mixture in the range of $11-17^{\circ}$ and $33-37^{\circ}$, respectively. The sharp peaks of DTXL were also found in the formulation CNP3 in the range of $11-17^{\circ}$ that depicted the crystalline nature of the formulation as shown in Figure $3 .^{44}$

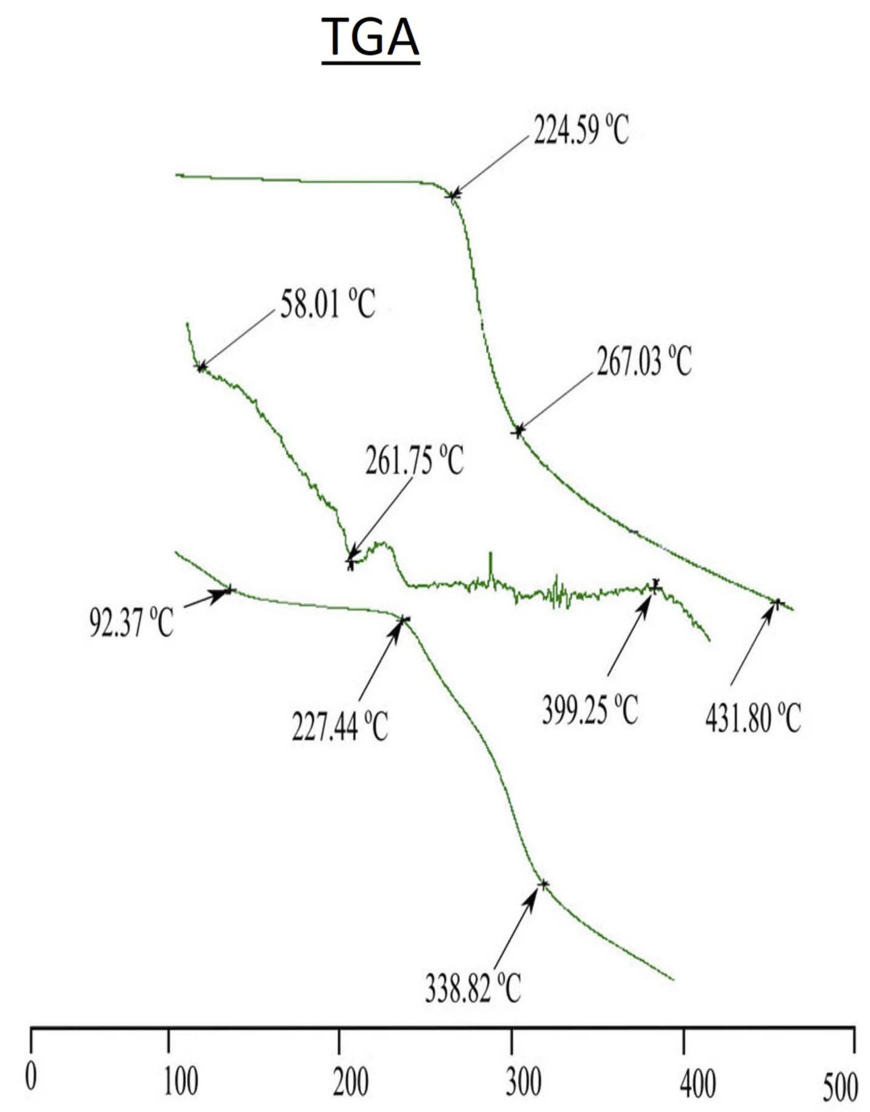

Figure 2 DSC and TGA (Drug, physical mixture, formulation CNP3). 
A

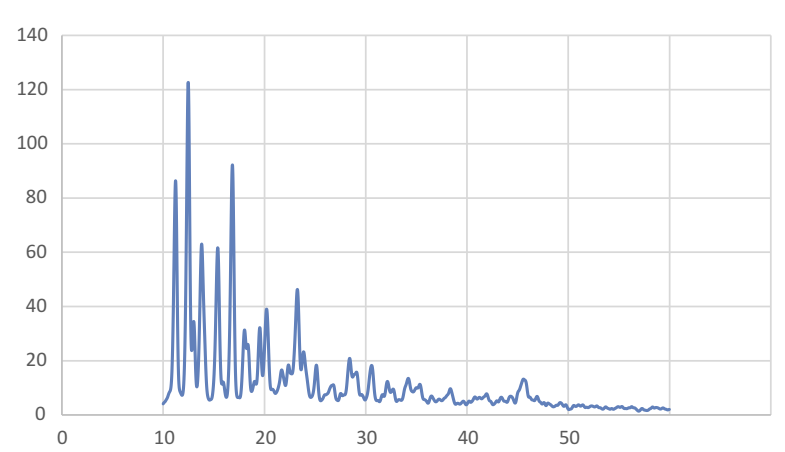

C

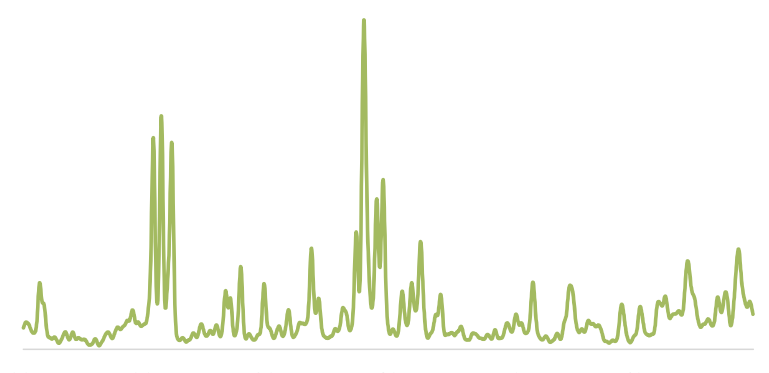

$10 \quad 20$

$\mathbf{E}$

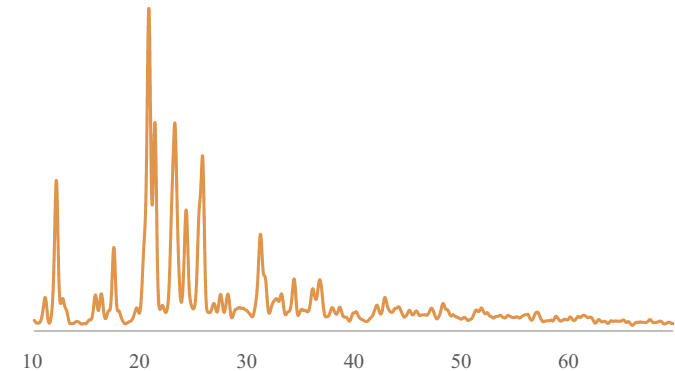

B

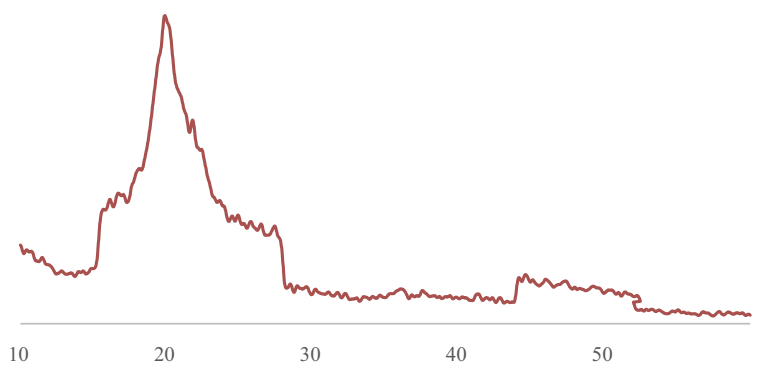

D

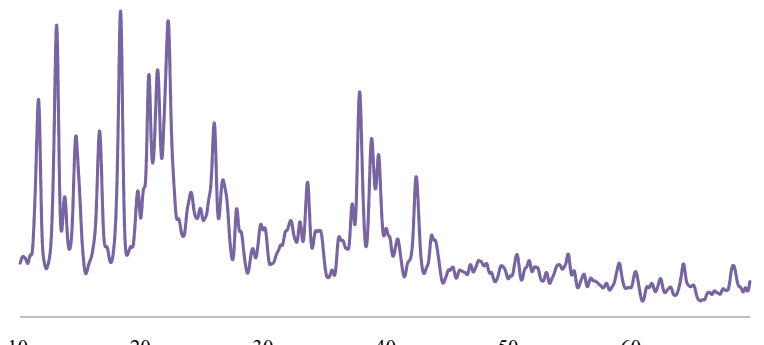

10

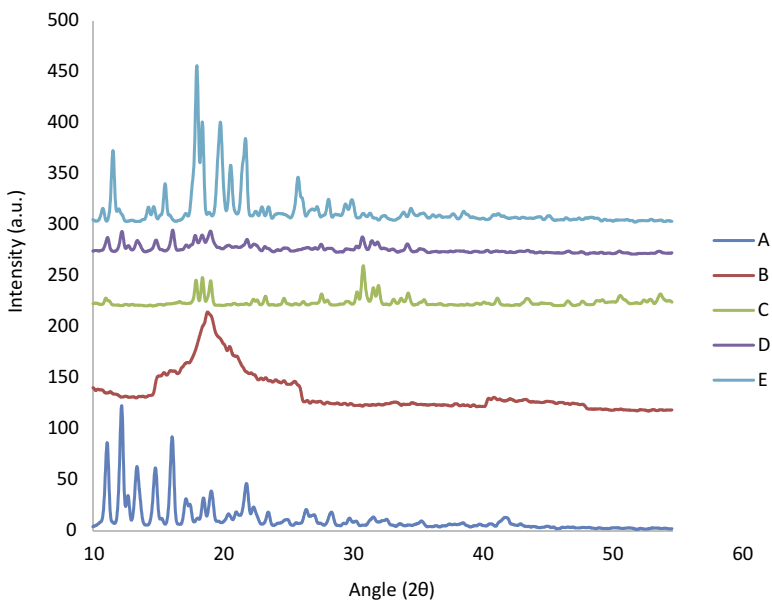

Figure 3 XRD of DTXL (A), chitosan (B), STPP (C), physical mixture (D) and formulation CNP3 (E).

Fourier Transform Infrared Spectroscopy (FTIR) Analysis

DTXL showed characteristic peaks at $3477 \mathrm{~cm}^{-1}$ mimicking with N-H stretching of alkanes, ${ }^{25} 2990 \mathrm{~cm}^{-1}$ due to $\mathrm{C}-\mathrm{H}$ stretching, ${ }^{45} 1713 \mathrm{~cm}^{-1}$ due to $\mathrm{C}=\mathrm{O}$ stretching, ${ }^{25}$ $1490 \mathrm{~cm}^{-1}$ associated with $\mathrm{C}=\mathrm{C}$ stretching, ${ }^{45}$ and $1246 \mathrm{~cm}^{-1}$ indicated the C-N stretching vibration of DTX (Figure 4). ${ }^{46}$ The characteristic peaks of chitosan were observed at $3296 \mathrm{~cm}^{-1}$ depicted stretching vibration of $-\mathrm{OH}$ groups, $1644 \mathrm{~cm}^{-1}$ described $\mathrm{C}=\mathrm{O}$ of acetamide group, ${ }^{47,48}$ $1526 \mathrm{~cm}^{-1}$ represented $-\mathrm{NH}$ bending vibration of $\mathrm{NH}_{2}$ group $^{48}$ and $1063 \mathrm{~cm}^{-1}$ showed $-\mathrm{CN}$ and $-\mathrm{CO}$ stretching vibration. ${ }^{47}$ The characteristic peaks of STPP at the wavenumber of $1129 \mathrm{~cm}^{-1}$ provided the recognition of the occurrence of phosphate group. ${ }^{49,50}$ Physical mixture also showed characteristic peaks of drug and STPP with slight shifting at $2900 \mathrm{~cm}^{-1}$ and $1711 \mathrm{~cm}^{-1}$, respectively. The PNPs showed the peak at $2767 \mathrm{~cm}^{-1}$ that might be due to the overlapping of the wavenumber peaks between drug and chitosan. Similarly, PNPs also showed the characteristic drug peak of STPP at $1708 \mathrm{~cm}^{-1}$.

The presence of peaks of DTXL in the physical mixture and optimized formulation (CNP3) ensures the absence of chemical interaction of the drug with formulation components and stability of the developed PNPs. ${ }^{51}$ Together with 


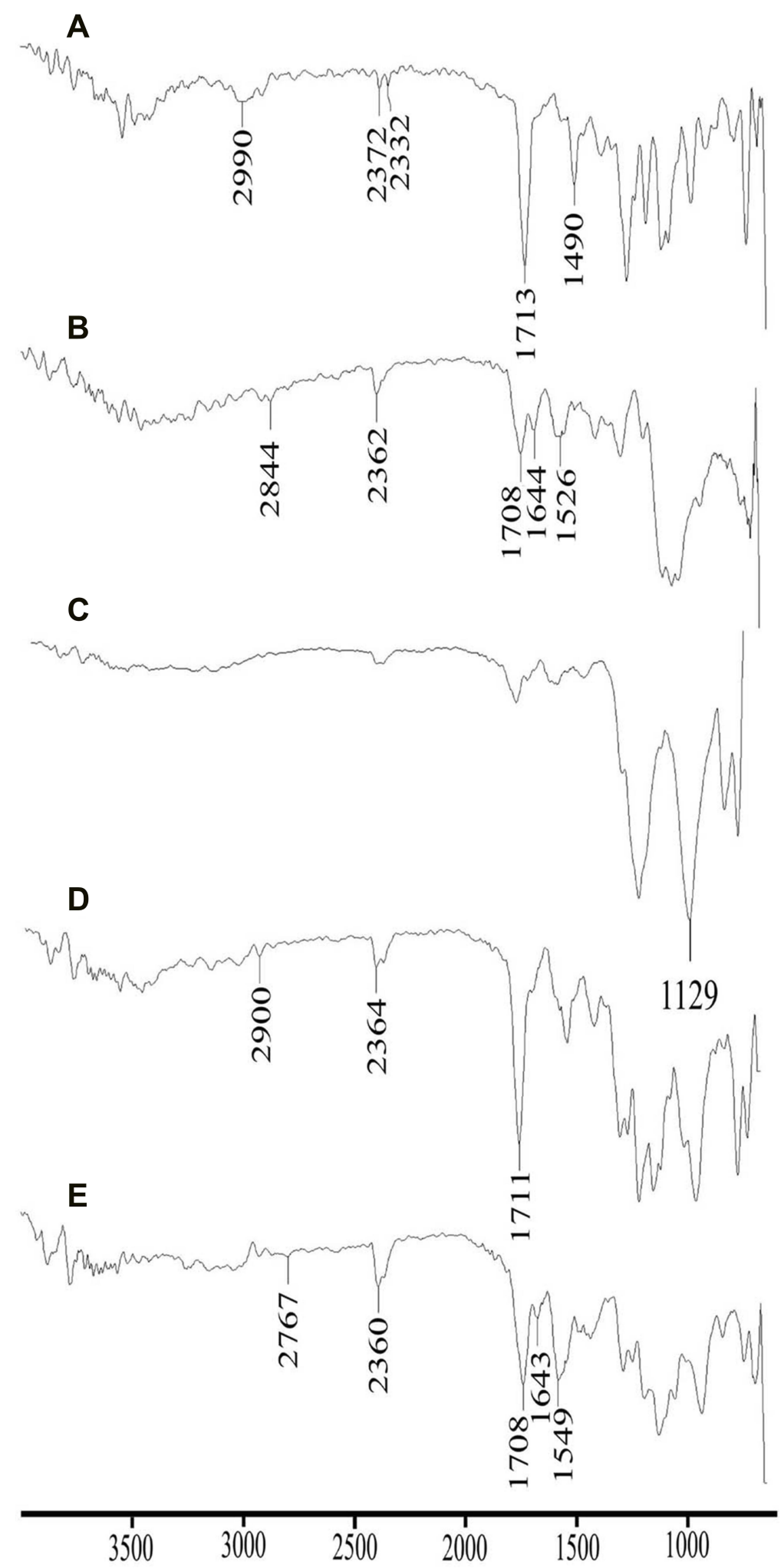

Figure 4 Comparative FTIR spectra of DTXL (A), chitosan (B), STPP (C), physical mixture (D) and formulation CNP3 (E).

the results of zeta potential, PXRD and FTIR, it was are stable and will also form a stable colloidal dispersion assumed that the PNP formulations prepared in this study which is a prerequisite for biomedical applications. 


\section{In-vitro Drug Release Studies and Kinetic Modeling}

Cumulative drug release over 24 hrs study period was found to be in the range of $51.57 \%$ (CNP5) to $69.93 \%$ (CNP3) which depicts a sustained release behavior (Figure 5). Initially, the drug release is faster ${ }^{31}$ due to the rapid dissolution of surface entrapped/adhered DTXL followed by a second sustained release phase. ${ }^{52}$ The final slower release phase may correspond to the release of DTXL from the core as a result of chitosan hydration and swelling. Higher values of the correlation coefficient are observed for the Korsmeyer-Peppas model so it was concluded that the release of DTXL from CNPs predominantly followed the KorsmeyerPeppas model. According to this model, the value of release exponent " $n$ " was below 0.45 that depicts drug release from CNPs by diffusion mechanism (Table 3). Comparable results of the drug release mechanism were previously reported. ${ }^{53}$

\section{Acute Oral Toxicity Study Evaluation}

Improved tolerability of potent drugs is the main advantage of different nanoscale drug delivery systems available in market. ${ }^{54}$ Also, the drug delivery systems must lack the toxicity of their own. ${ }^{29}$ Therefore, the acute oral toxicity studies were performed as shown in Table 4.

\section{Biochemical Analysis of Blood}

The components used for the synthesis of polymeric nanoparticles including polymer and surfactant formed by solvent evaporation technique undergo various challenges when introduced into the body. Besides releasing the drug in-vivo, the formulation components might leach

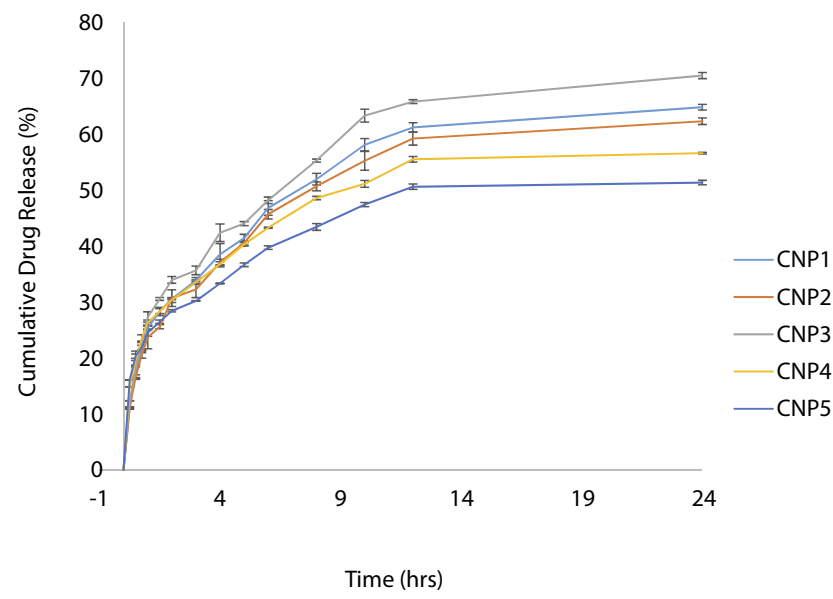

Figure 5 Cumulative drug release of polymeric nanoparticles.
Table 3 Kinetic Modeling of Drug Release Profile of Chitosan Nanoparticles

\begin{tabular}{|l|l|l|l|l|l|}
\hline $\begin{array}{l}\text { Formulation } \\
\text { Code }\end{array}$ & $\begin{array}{l}\text { Zero } \\
\text { Order }\end{array}$ & $\begin{array}{l}\text { First } \\
\text { Order }\end{array}$ & $\begin{array}{l}\text { Higuchi } \\
\text { Model }\end{array}$ & \multicolumn{2}{|l|}{$\begin{array}{l}\text { Korsmeyer- } \\
\text { Peppas } \\
\text { Model }\end{array}$} \\
\cline { 2 - 6 } & $\boldsymbol{R}^{\mathbf{2}}$ & $\boldsymbol{R}^{\mathbf{2}}$ & $\boldsymbol{R}^{\mathbf{2}}$ & $\boldsymbol{R}^{\mathbf{2}}$ & $\mathbf{n}$ \\
\hline CNPI & 0.1796 & 0.6131 & 0.8573 & 0.9734 & 0.338 \\
CNP2 & 0.1639 & 0.5962 & 0.8616 & 0.9734 & 0.340 \\
CNP3 & 0.1598 & 0.6739 & 0.8624 & 0.9744 & 0.340 \\
CNP4 & 0.7360 & 0.2047 & 0.7018 & 0.9769 & 0.279 \\
CNP5 & 0.9048 & 0.0139 & 0.6478 & 0.9786 & 0.264 \\
\hline
\end{tabular}

Table 4 Clinical Observations of an Acute Oral Toxicity Study for Prepared Chitosan Loaded Nanoparticles

\begin{tabular}{|c|c|c|}
\hline Observation & $\begin{array}{l}\text { Group I (Treated with } \\
\text { CNPs) Mean } \pm \text { SD }\end{array}$ & $\begin{array}{l}\text { Group II } \\
\text { (Control) Mean } \\
\pm \text { SD }\end{array}$ \\
\hline Signs of illness & Nil & Nil \\
\hline \multicolumn{3}{|c|}{ Body Weight (in grams) } \\
\hline 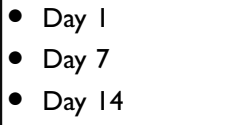 & $\begin{array}{l}172.42 \pm 0.42 \\
193.08 \pm 0.31 \\
206.83 \pm 0.47\end{array}$ & $\begin{array}{l}167.25 \pm 0.35 \\
197.17 \pm 0.31 \\
207.83 \pm 0.66\end{array}$ \\
\hline $\begin{array}{l}\text { Any visible skin } \\
\text { irritation/ toxicity } \\
\text { Ocular toxicity } \\
\text { Mortality }\end{array}$ & $\begin{array}{l}\text { Nil } \\
\text { Nil } \\
\text { Nil }\end{array}$ & $\begin{array}{l}\text { Nil } \\
\text { Nil } \\
\text { Nil }\end{array}$ \\
\hline
\end{tabular}

out of the formulation. Therefore, toxicity study was carried out to check the various parameters including hematological, biochemical and histopathological aspects. The study was conducted using the OECD guideline 420.

For the hematological analysis, blood samples were collected from the rats via retro-orbital plexus, immediately transferred to EDTA (ethylene diamine tetraacetate) tubes to prevent coagulation of collected blood. The parameters checked in the hematological examination are given in Table 5. Hematological values of CNPs treated rats were comparable with control group which depicts acceptable biocompatibility and bio acceptance of developed formulations (Table 5).

\section{Liver and Kidney Function Tests}

The liver and kidney function tests of both groups have been presented in Table 6. ALT, alkaline phosphate, bilirubin, AST, urea, and creatinine showed comparable results for test and control group depicting the safety and biocompatibility of developed CNPs. 
Table 5 Biochemical Blood Analysis

\begin{tabular}{|l|l|l|}
\hline Hematology & $\begin{array}{l}\text { Group I (CNPs) } \\
\text { Mean } \pm \text { SD }\end{array}$ & $\begin{array}{l}\text { Group II } \\
\text { (Control) } \\
\text { Mean } \pm \text { SD }\end{array}$ \\
\hline Hemoglobin $(\mathrm{g} / \mathrm{dL})$ & $13.3 \pm 0.01$ & $13.20 \pm 0.14$ \\
Red blood cells $\times 10^{6}(\mu \mathrm{L})$ & $6.99 \pm 0.07$ & $6.94 \pm 0.05$ \\
Platelets $\times 10^{3}(\mu \mathrm{L})$ & $924.75 \pm 3.96$ & $928.50 \pm 4.72$ \\
White blood cells $\times 10^{3}(\mu \mathrm{L})$ & $7.58 \pm 0.38$ & $7.93 \pm 0.33$ \\
Lymphocytes $(\%)$ & $89.08 \pm 1.06$ & $88.38 \pm 0.41$ \\
Neutrophils $(\%)$ & $8.23 \pm 0.59$ & $8.75 \pm 0.38$ \\
Mean corpuscular volume $(\mathrm{fL})$ & $67.38 \pm 0.71$ & $67.83 \pm 0.48$ \\
Mean corpuscular hemoglobin & $28.34 \pm 0.03$ & $28.41 \pm 0.06$ \\
concentration $(\mathrm{g} / \mathrm{dL})$ & & $19.20 \pm 0.22$ \\
Mean corpuscular hemoglobin $(\mathrm{pg})$ & $18.95 \pm 0.11$ & \\
\hline
\end{tabular}

Note: All values are given as mean plus or minus the standard deviation $(n=3)$.

Table 6 Liver and Kidney Function Tests

\begin{tabular}{|c|c|c|}
\hline Liver and Kidney Tests & $\begin{array}{l}\text { Group I (CNPs) } \\
\text { Mean } \pm \text { SD }\end{array}$ & $\begin{array}{l}\text { Group II (Control) } \\
\text { Mean } \pm \text { SD }\end{array}$ \\
\hline ALT (U/L) & $73.88 \pm 0.74$ & $73.13 \pm 1.88$ \\
\hline Alkaline phosphatase $(\mathrm{g} / \mathrm{dL})$ & $115.75 \pm 3.77$ & $113.25 \pm 4.66$ \\
\hline Bilirubin (mg/dL) & $0.31 \pm 0.01$ & $0.37 \pm 0.02$ \\
\hline AST (U/L) & $122 \pm 2.24$ & $123 \pm 2.45$ \\
\hline Urea $(\mathrm{mg} / \mathrm{dL})$ & $46.75 \pm 2.28$ & $45.75 \pm 1.92$ \\
\hline Creatinine $(\mathrm{mg} / \mathrm{dL})$ & $0.38 \pm 0.06$ & $0.41 \pm 0.04$ \\
\hline
\end{tabular}

Note: All values are given as mean plus or minus the standard deviation $(n=3)$.

\section{Histopathological Examination}

Histological examination is used to visualize any unusual change in biological tissues due to toxicity. ${ }^{55}$ In this study, no animal died during the study as shown in Figure 6. Furthermore, no pathological change, lesion, disruption or deformation were observed in the vital organs of the control as well as group I administered with CNPs. The lack of abnormal changes also shows the safety and compatibility in agreement with previous results. ${ }^{56}$ Therefore, the result of our acute oral toxicity study indicated that the CNPs developed were not toxic to Wistar rats and are acceptable for the delivery of various drugs. ${ }^{57}$ Results are in agreement with previous findings while evaluation of CNPs safety with the aim to deliver quercetin. ${ }^{58}$

\section{Conclusion}

The docetaxel loaded polymeric nanoparticles were successfully developed by the ionic-gelation method and characterized for post-formulation parameters including physicochemical analysis, in-vitro drug release, and acute oral toxicity study. All the CNP formulations showed desirable size with good mono-dispersity, EE and LC depicts the effect

\section{Group I}
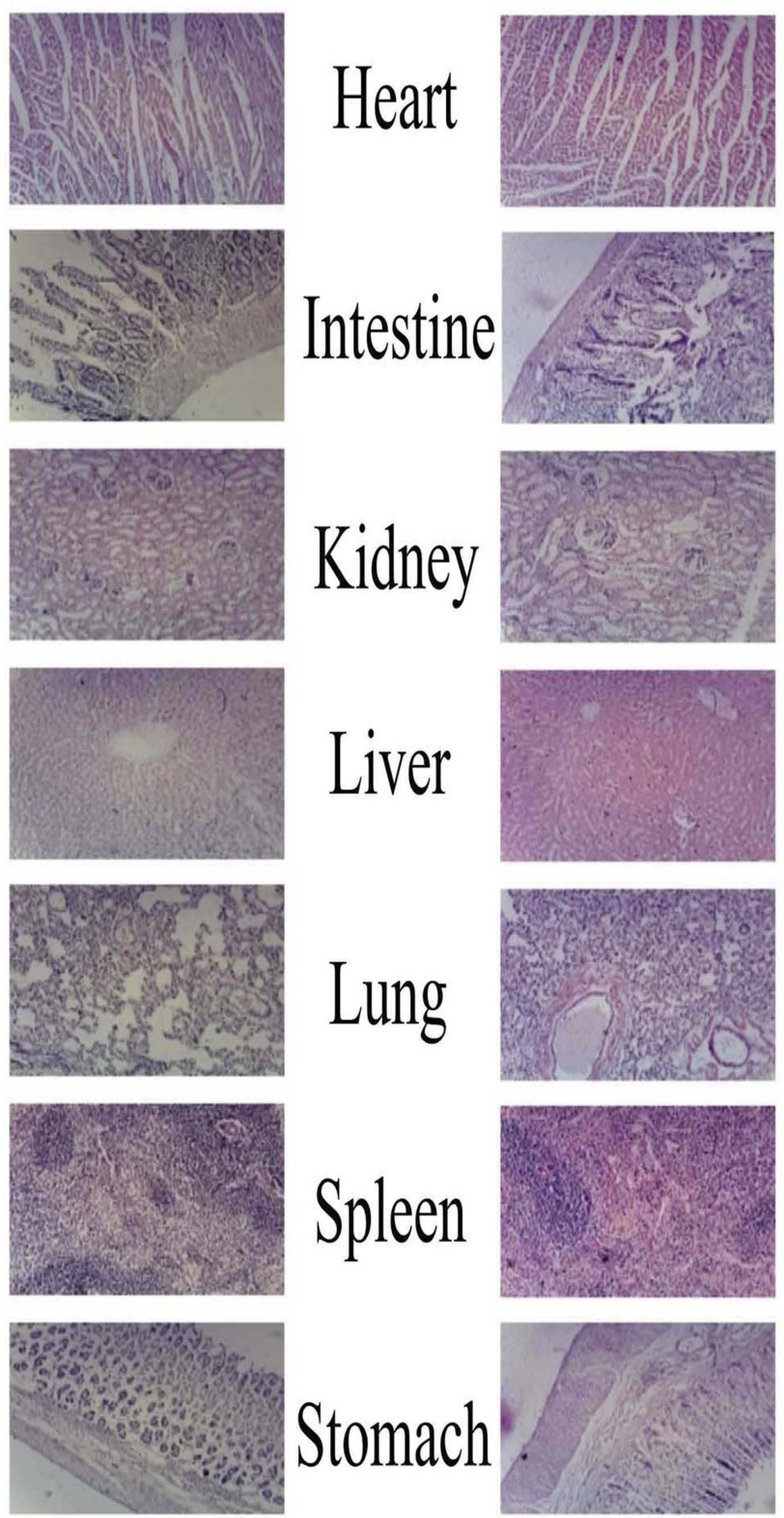

Figure 6 Histopathological microscopic examination of different tissues of wistar rats of group-I (test), and group-II (control).

of STPP concentration, in-vitro drug release studies showed docetaxel release up-to 24 hrs. DSC, TGA, PXRD, and FTIR studies confirmed thermal stability, physical state, and compatibility of DTXL with formulation components. Acute oral toxicity studies showed that chitosan-based PNPs were nontoxic and biocompatible for the delivery of docetaxel. Therefore, the chitosan NPs provide a potential drug delivery platform for the delivery of DTXL for the treatment of various types of cancers. 


\section{Acknowledgments}

The authors acknowledge the Higher Education Commission for providing a research support grant under the Indigenous Scholarship Program. The authors are also thankful to Prof. Dr. Naveed Akhtar, Dean, Faculty of Pharmacy and Alternative Medicines, The Islamia University of Bahawalpur, Bahawalpur, Pakistan, for excellent provision of research facilities, guidance and help to carry out the present research work.

\section{Disclosure}

The authors declare no conflicts of interest in this work.

\section{References}

1. WHO. Cancer; 2018. Available from: https://www.who.int/newsroom/fact-sheets/detail/cancer. Accessed September 12, 2018.

2. Siegel RL, Miller KD, Jemal A. Cancer statistics. CA Cancer J Clin. 2018;68(1):7-30. doi:10.3322/caac.21442

3. Xu X, Ho W, Zhang X, Bertrand N, Farokhzad O. Cancer nanomedicine: from targeted delivery to combination therapy. Trends $\mathrm{Mol}$ Med. 2015;21(4):223-232. doi:10.1016/j.molmed.2015.01.001

4. Bamrungsap S, Zhao Z, Chen T, et al. Nanotechnology in therapeutics: a focus on nanoparticles as a drug delivery system. Nanomedicine (Lond). 2012;7(8):1253-1271. doi:10.2217/nnm.12.87

5. Acharya S, Sahoo SK. PLGA nanoparticles containing various anticancer agents and tumour delivery by EPR effect. Adv Drug Deliv Rev. 2011;63(3):170-183. doi:10.1016/j.addr.2010.10.008

6. Moghimi SM, Hunter AC, Murray JC. Long-circulating and target-specific nanoparticles: theory to practice. Pharmacol Rev 2001;53(2):283-318

7. Kumari A, Yadav SK, Yadav SC. Biodegradable polymeric nanoparticles based drug delivery systems. Colloids Surf B Biointerfaces. 2010;75(1):1-18. doi:10.1016/j.colsurfb.2009.09.001

8. Qi L, Xu Z, Jiang X, Hu C, Zou X. Preparation and antibacterial activity of chitosan nanoparticles. Carbohydr Res. 2004;339 (16):2693-2700. doi:10.1016/j.carres.2004.09.007

9. Abd El Hady WE, Mohamed EA, Soliman OAE, El-Sabbagh HM. In vitro-in vivo evaluation of chitosan-PLGA nanoparticles for potentiated gastric retention and anti-ulcer activity of diosmin. Int J Nanomedicine. 2019;14:7191-7213. doi:10.2147/IJN.S213836

10. Stenger Moura FC, Perioli L, Pagano C, et al. Chitosan composite microparticles: a promising gastroadhesive system for taxifolin. Carbohydr Polym. 2019;218:343-354. doi:10.1016/j.carbpol.2019.04.075

11. Tsai L-C, Chen C-H, Lin C-W, Ho Y-C, Mi F-L. Development of multifunctional nanoparticles self-assembled from trimethyl chitosan and fucoidan for enhanced oral delivery of insulin. Int $J$ Biol Macromol. 2019;126:141-150. doi:10.1016/j.ijbiomac.2018.12.182

12. Malik A, Gupta M, Gupta V, Gogoi H, Bhatnagar R. Novel application of trimethyl chitosan as an adjuvant in vaccine delivery. Int J Nanomed. 2018;13:7959-7970. doi:10.2147/IJN

13. Anitha A, Deepagan VG, Divya Rani VV, Menon D, Nair SV, Jayakumar R. Preparation, characterization, in vitro drug release and biological studies of curcumin loaded dextran sulphate-chitosan nanoparticles. Carbohydr Polym. 2011;84(3):1158-1164. doi:10.1016/j. carbpol.2011.01.005

14. Cortes JE, Pazdur R. Docetaxel. J Clin Oncol. 1995;13 (10):2643-2655. doi:10.1200/JCO.1995.13.10.2643

15. Jibodh RA, Lagas JS, Nuijen B, Beijnen JH, Schellens JHM. Taxanes: old drugs, new oral formulations. Eur $J$ Pharmacol. 2013;717(1):40-46. doi:10.1016/j.ejphar.2013.02.058
16. Jeetah R, Bhaw-Luximon A, Jhurry D. Polymeric nanomicelles for sustained delivery of anti-cancer drugs. Mutat Res. 2014;768:47-59. doi:10.1016/j.mrfmmm.2014.04.009

17. Feng -S-S, Mei L, Anitha P, Gan CW, Zhou W. Poly(lactide)-vitamin E derivative/montmorillonite nanoparticle formulations for the oral delivery of docetaxel. Biomaterials. 2009;30(19):3297-3306. doi:10.1016/j.biomaterials.2009.02.045

18. Thanki K, Gangwal RP, Sangamwar AT, Jain S. Oral delivery of anticancer drugs: challenges and opportunities. $J$ Control Release. 2013;170(1):15-40. doi:10.1016/j.jconrel.2013.04.020

19. Calvo P, Remunan-Lopez C, Vila-Jato JL, Alonso M. Novel hydrophilic chitosan-polyethylene oxide nanoparticles as protein carriers. J Appl Polym Sci. 1997;63(1):125-132. doi:10.1002/(SICI)10974628(19970103)63:1<125::AID-APP13>3.0.CO;2-4

20. Rama K, Senapati P, Das M. Formulation and in vitro evaluation of ethyl cellulose microspheres containing zidovudine. $J$ Microencapsul. 2005;22(8):863-876. doi:10.1080/02652040500273498

21. Tahir N, Madni A, Balasubramanian V, et al. Development and optimization of methotrexate-loaded lipid-polymer hybrid nanoparticles for controlled drug delivery applications. Int J Pharm. 2017;533 (1):156-168. doi:10.1016/j.ijpharm.2017.09.061

22. Rehman M, Ihsan A, Madni A, et al. Solid lipid nanoparticles for thermoresponsive targeting: evidence from spectrophotometry, electrochemical, and cytotoxicity studies. Int $J$ Nanomed. 2017;12:8325-8336. doi:10.2147/IJN

23. Twu Y-K, Chen Y-W, Shih C-M. Preparation of silver nanoparticles using chitosan suspensions. Powder Technol. 2008;185(3):251-257. doi:10.1016/j.powtec.2007.10.025

24. Bobal P, Sujan J, Otevrel J, Imramovsky A, Padelkova Z, Jampilek J. Microwave-assisted synthesis of new substituted anilides of quinaldic acid. Molecules. 2012;17(2):1292. doi:10.3390/ molecules 17021292

25. Jain A, Thakur K, Kush P, Jain UK. Docetaxel loaded chitosan nanoparticles: formulation, characterization and cytotoxicity studies. Int J Biol Macromol. 2014;69:546-553. doi:10.1016/j.ijbiomac. 2014.06.029

26. Madni A, Rahim MA, Mahmood MA, et al. Enhancement of dissolution and skin permeability of pentazocine by proniosomes and niosomal gel. AAPS Pharm Sci Tech. 2018;19(4):1544-1553. doi:10.1208/s12249-018-0967-6

27. OECD G. 420. acute oral toxicity-fixed dose procedure. OECD Guidelines for the Testing of Chemicals; 2001.

28. Kleine-Brueggeney H, Zorzi GK, Fecker T, El Gueddari NE, Moerschbacher BM, Goycoolea FM. A rational approach towards the design of chitosan-based nanoparticles obtained by ionotropic gelation. Colloids Surf B Biointerfaces. 2015;135:99-108. doi:10.1016/j.colsurfb.2015.07.016

29. Umair M, Javed I, Rehman M, et al. Nanotoxicity of inert materials: the case of gold, silver and iron. J Pharm Pharm Sci. 2016;19 (2):161-180. doi:10.18433/J31021

30. Alasvand N, Urbanska AM, Rahmati M, et al. Chapter 13 - therapeutic nanoparticles for targeted delivery of anticancer drugs. In: Grumezescu AM, editor. Multifunctional systems for combined delivery, biosensing and diagnostics. Elsevier; 2017:245-259.

31. Wu J, Wang Y, Yang H, Liu X, Lu Z. Preparation and biological activity studies of resveratrol loaded ionically cross-linked chitosan-TPP nanoparticles. Carbohydr Polym. 2017;175:170-177. doi:10.1016/j.carbpol.2017.07.058

32. Sreekumar S, Goycoolea FM, Moerschbacher BM, Rivera-rodriguez GR. Parameters influencing the size of chitosan-TPP nano- and microparticles. Sci Rep. 2018;8(1):4695. doi:10.1038/s41598-01823064-4

33. Chang Y-C, Chen D-H. Preparation and adsorption properties of monodisperse chitosan-bound $\mathrm{Fe} 3 \mathrm{O} 4$ magnetic nanoparticles for removal of $\mathrm{Cu}$ (II) ions. J Colloid Interface Sci. 2005;283 (2):446-451. doi:10.1016/j.jcis.2004.09.010 
34. de Pinho Neves AL, Milioli CC, Müller L, Riella HG, Kuhnen NC, Stulzer HK. Factorial design as tool in chitosan nanoparticles development by ionic gelation technique. Colloids Surf a Physicochem Eng Asp. 2014;445:34-39. doi:10.1016/j.colsurfa.2013.12.058

35. Derakhshandeh K, Fathi S. Role of chitosan nanoparticles in the oral absorption of Gemcitabine. Int J Pharm. 2012;437(1):172-177. doi:10.1016/j.ijpharm.2012.08.008

36. Hassani S, Laouini A, Fessi H, Charcosset C. Preparation of chitosanTPP nanoparticles using microengineered membranes - effect of parameters and encapsulation of tacrine. Colloids Surf A Physicochem Eng Asp. 2015;482:34-43. doi:10.1016/j.colsurfa.2015.04.006

37. Nimesh S. Gene therapy: Potential applications of nanotechnology. 1st ed. Elsevier; 2013

38. Yang W, Fu J, Wang T, He N. Chitosan/sodium tripolyphosphate nanoparticles: preparation, characterization and application as drug carrier. J Biomed Nanotechnol. 2009;5(5):591-595. doi:10.1166/jbn.2009.1067

39. Yuan D, Jacquier JC, O'Riordan ED. Entrapment of protein in chitosan-tripolyphosphate beads and its release in an in vitro digestive model. Food Chem. 2017;229:495-501. doi:10.1016/j.foodchem.2017. 02.107 .

40. Jana S, Maji N, Nayak AK, Sen KK, Basu SK. Development of chitosan-based nanoparticles through inter-polymeric complexation for oral drug delivery. Carbohydr Polym. 2013;98(1):870-876. doi:10.1016/j.carbpol.2013.06.064

41. Khanmohammadi M, Elmizadeh $\mathrm{H}$, Ghasemi K. Investigation of size and morphology of chitosan nanoparticles used in drug delivery system employing chemometric technique. Iran $J$ Pharm Res. 2015;14(3):665.

42. Bilensoy E, Sarisozen C, Esendağlı G, et al. Intravesical cationic nanoparticles of chitosan and polycaprolactone for the delivery of Mitomycin C to bladder tumors. Int J Pharm. 2009;371(1-2):170-176. doi:10.1016/j.ijpharm.2008.12.015

43. Zhu H, Chen H, Zeng X, et al. Co-delivery of chemotherapeutic drugs with vitamin E TPGS by porous PLGA nanoparticles for enhanced chemotherapy against multi-drug resistance. Biomaterials. 2014;35(7):2391-2400. doi:10.1016/j.biomaterials.2013.11.086

44. Fang G, Tang B, Liu Z, et al. Novel hydrophobin-coated docetaxel nanoparticles for intravenous delivery: in vitro characteristics and in vivo performance. Eur J Pharm Sci. 2014;60:1-9. doi:10.1016/j. ejps.2014.04.016

45. Hammadi NI, Abba Y, Hezmee MNM, et al. Formulation of a sustained release docetaxel loaded cockle shell-derived calcium carbonate nanoparticles against breast cancer. Pharm Res. 2017;34 (6):1193-1203. doi:10.1007/s11095-017-2135-1

46. Nasrollahi F, Varshosaz J, Khodadadi AA, Lim S, JahanianNajafabadi A. Targeted delivery of docetaxel by use of transferrin/ poly(allylamine hydrochloride)-functionalized graphene oxide nanocarrier. ACS Appl Mater Interfaces. 2016;8(21):13282-13293. doi:10.1021/acsami.6b02790
47. Radwan SE-S, Sokar MS, Abdelmonsif DA, El-Kamel AH. Mucopenetrating nanoparticles for enhancement of oral bioavailability of furosemide: in vitro and in vivo evaluation/sub-acute toxicity study. Int J Pharm. 2017;526(1):366-379. doi:10.1016/j.ijpharm. 2017.04.072

48. Mukhopadhyay P, Chakraborty S, Bhattacharya S, Mishra R, Kundu PP. pH-sensitive chitosan/alginate core-shell nanoparticles for efficient and safe oral insulin delivery. Int $J$ Biol Macromol. 2015;72:640-648. doi:10.1016/j.ijbiomac.2014.08.040

49. Pati F, Adhikari B, Dhara S. Development of chitosan-tripolyphosphate fibers through $\mathrm{pH}$ dependent ionotropic gelation. Carbohydr Res. 2011;346(16):2582-2588. doi:10.1016/j.carres.2011.08.028

50. Hejjaji EMA, Smith AM, Morris GA. Designing chitosan-tripolyphosphate microparticles with desired size for specific pharmaceutical or forensic applications. Int J Biol Macromol. 2017;95:564-573. doi:10.1016/j.ijbiomac.2016.11.092

51. Bagre AP, Jain K, Jain NK. Alginate coated chitosan core shell nanoparticles for oral delivery of enoxaparin: in vitro and in vivo assessment. Int $J$ Pharm. 2013;456(1):31-40. doi:10.1016/j. ijpharm.2013.08.037

52. Bugnicourt L, Ladavière C. Interests of chitosan nanoparticles ionically cross-linked with tripolyphosphate for biomedical applications. Prog Polym Sci. 2016;60:1-17. doi:10.1016/j.progpolymsci.2016. 06.002

53. Saremi S, Atyabi F, Akhlaghi SP, Ostad SN, Dinarvand R. Thiolated chitosan nanoparticles for enhancing oral absorption of docetaxel: preparation, in vitro and ex vivo evaluation. Int $J$ Nanomed. 2011;6:119-128. doi:10.2147/IJN.S15500

54. Madni A, Sarfraz M, Rehman M, et al. Liposomal drug delivery: a versatile platform for challenging clinical applications. $J$ Pharm Pharm Sci. 2014;17(3):401-426. doi:10.18433/J3CP55

55. Sreejayan N, Marone PA, Lau FC, Yasmin T, Bagchi M, Bagchi D. Safety and toxicological evaluation of a novel chromium (III) dinicocysteinate complex. Toxicol Mech Methods. 2010;20(6):321-333. doi: 10.3109/15376516.2010.487880

56. Udeh NE, Anaga A, Asuzu IU. Acute and sub-chronic oral toxicity studies on methanol leaf extract of Gnetum africanum Welw in wistar rats. Am J Res Med Sci. 2018;3(1):7-14.

57. Raina P, Chandrasekaran C, Deepak M, Agarwal A, Ruchika K-G. Evaluation of subacute toxicity of methanolic/aqueous preparation of aerial parts of $\mathrm{O}$. sanctum in Wistar rats: clinical, haematological, biochemical and histopathological studies. $J$ Ethnopharmacol. 2015;175:509-517. doi:10.1016/j.jep.2015.10.015

58. Mohammed MA, Syeda JTM, Wasan KM, Wasan EK. An overview of chitosan nanoparticles and its application in non-parenteral drug delivery. Pharmaceutics. 2017;9(4):53. doi:10.3390/pharmaceutics 9040053
International Journal of Nanomedicine

\section{Publish your work in this journal}

The International Journal of Nanomedicine is an international, peerreviewed journal focusing on the application of nanotechnology in diagnostics, therapeutics, and drug delivery systems throughout the biomedical field. This journal is indexed on PubMed Central, MedLine, CAS, SciSearch ${ }^{\mathbb{R}}$, Current Contents ${ }^{\mathbb{R}} /$ Clinical Medicine, $^{2}$
Journal Citation Reports/Science Edition, EMBase, Scopus and the Elsevier Bibliographic databases. The manuscript management system is completely online and includes a very quick and fair peer-review system, which is all easy to use. Visit http://www.dovepress.com/ testimonials.php to read real quotes from published authors. 